\title{
MORINGA TEA BLOCKS ACUTE LUNG INFLAMMATION INDUCED BY SWINE CONFINEMENT DUST THROUGH A MECHANISM INVOLVING TNF- $\alpha$ EXPRESSION, C-JUN N-TERMINAL KINASE ACTIVATION AND NEUTROPHIL REGULATION
}

\author{
${ }^{1}$ Mykea Mcknight, ${ }^{1}$ Jabria Allen, ${ }^{1}$ Jenora T. Waterman, \\ ${ }^{1}$ Steven Hurley, ${ }^{2}$ Joshua Idassi and ${ }^{1}$ Radiah C. Minor \\ ${ }^{1}$ Department of Animal Sciences, \\ ${ }^{2}$ The Cooperative Extension Program, \\ School of Agriculture and Environmental Sciences, \\ North Carolina Agricultural and Technical State University, 1601 E. Market St. Greensboro, NC, 27411, USA
}

Received 2014-03-21; Revised 2014-04-01; Accepted 2014-05-08

\begin{abstract}
Plant based products represent a promising alternative to conventional treatments for inflammation. Moringa oleifera Lam is a tree rich in proteins, vitamins, minerals and a variety of phytochemcals with health benefits. Among the reported health benefits are antioxidant and anti-inflammatory properties. The purpose of this study was to investigate whether tea brewed from dried Moringa leaves would abrogate inflammation in a mouse model of acute lung inflammation induced by LPS or extracts prepared from dust collected from a swine confinement facility (DE). Mice were offered water or Moringa tea for seven days. Tea consumption was significantly greater than that of water consumption on days 1 and 6, but there were no significant differences in weight gain or food consumption. On day seven, mice from both groups were forced to inhale, via intranasal challenge, either Phosphate Buffered Saline (PBS), Lipopolysaccharide (LPS) [10 $\mu \mathrm{g} \mathrm{mL} \mathrm{mL}^{-1}$ ] or DE [10\%]. Compared to mice that drank water, mice that drank Moringa tea had significantly less protein $(p<0.05)$ and cellular influx $(\mathrm{p}<0.0001)$ into the lung after inhalation of $10 \% \mathrm{DE}$. No difference in neutrophil migration into the lungs of water and M. tea groups after LPS or DE challenge was detected. But mice that drank tea had significantly $(\mathrm{p}<0.05)$ more neutrophils with apoptotic morphology after DE challenge. TNF- $\alpha$ expression $24 \mathrm{~h}$ after inhalation of $10 \% \mathrm{DE}$, was significantly higher $(\mathrm{p}<0.05)$ in lungs of $\mathrm{M}$. tea mouse group as compared to water group. This increase in TNF- $\alpha$ was accompanied by higher levels of pro and anti-inflammatory cytokines. Finally, activation of c-Jun N-terminal Kinase (JNK) in lungs of M. tea+DE group $24 \mathrm{~h}$ post inhalation was decreased. Taken together these results suggest that Moringa oleifera leaf tea exerts antiinflammatory properties on acute lung inflammation induced by swine confinement dust through a mechanism involving neutrophil regulation and JNK activation.
\end{abstract}

Keywords: Inflammation, Lung, Agricultural Dust, Complimentary and Alternative Medicine

\section{INTRODUCTION}

Inflammation is a physiological response that protects a host against external and internal assault. It is the first response of a host to an infection or irritation, meant to destroy (or contain) a damaging agent, initiate repair and restore function of damaged tissue. In this instance, inflammation is a necessary and helpful process.

Corresponding Author: Radiah C. Minor, Department of Animal Sciences, School of Agriculture and Environmental Sciences, North Carolina Agricultural and Technical State University, 1601 E. Market St. Greensboro, NC. 27411, USA 
However, inflammation, particularly chronic or persistent low-grade inflammation can be associated with deleterious effects, can lead to tissue damage and is associated with chronic diseases like cancer, diabetes, heart disease allergies and asthma (Freund et al., 2010).

For decades, plant-based materials have been considered an important source of natural products used for health. Natural products continue to be important to consumers and recently there has been an increase in the popularity in Complementary and Alternative Medicine (CAM). Consumers increasingly demand such products to promote heath and prevent disease. According to a report by the Centers for Disease Control (CDC), the use of dietary supplements is common among the U.S. Adult population and it is estimated that over $50 \%$ of Americans over 20 years old report using supplements (Bailey et al., 2011).

Moringa oleifera, or Moringa is tree native to the sub-Himalayan regions of India, Pakistan, Bangladesh and Afghanistan, that is now widely cultivated and naturalized in many places around the globe including the US (Anwar et al., 2007). Moringa has healthpromoting bioactive and nutritive components that increase its potential as a natural supplement in treating disease. Among the many positive benefits, it has immune modulating, antioxidant and anti-inflammatory properties (Fahey, 2005; Muangnoi et al., 2012). All parts of the Moringa oleifera tree are edible and associated with health benefits. Eating the plant leaves, or consuming leaf-concentrate, or extract can positively affect health and immunity and immune cells (Fahey, 2005; Anwar et al., 2007). Experiments in guinea pigs has shown that $\beta$-sitosterol isolated from an n-butanol extract of Moringa oleifera seeds led to the synthesis and release of Th2 cytokines in a model for allergic asthma (Mahajan and Mehta, 2011). Methanolic extract of Moringa oleifera enhanced the phagocytosis of neutrophils while ethanolic extract $(50 \%)$ of $M$. oleifera leaves promoted phagocytosis by macrophages in the immunosuppressed mouse model (Sudha et al., 2010; Gupta et al., 2010). Ethanolic extract of Moringa seeds in contrast, showed immunosuppressive effect and caused down-regulation of macrophage phagocytosis of carbon particles (Mahajan and Mehta, 2010). Taken together, these data illustrate that different parts of the Moringa tree exhibit a myriad of immunomodulatory activities. Much of these modulatory activities require further exploration. The goal of this study was to investigate the immune modulating and antiinflammatory properties of tea prepared from Moringa leaves using a model of acute lung inflammation.

\section{MATERIALS AND METHODS}

\subsection{Preparation and Analysis of $1 \%$ (w/v) Moringa Tea}

Dried Moringa leaves (from plants grown in Winston-Salem NC) were used to prepare M. tea. Dried Moringa leaves $(30 \mathrm{~g})$ were steeped in $3 \mathrm{~L}$ of boiling hot distilled deionized water for $30 \mathrm{~min}$. After steeping, the M. tea was filtered through cheese cloth to remove large particles, then through a funnel lined with $3 \mathrm{M}$ filter paper to remove smaller particles. Finally, M. tea was filter sterilized through 0.22 micron filter and stored at $4^{\circ} \mathrm{C}$ until used.

\subsection{Preparation of Dust Extracts}

Dust extracts were prepared as previously described (Pender et al., 2014). Briefly, one gram of swine facility dust was combined with $10 \mathrm{~mL}$ of phosphate buffered saline solution without calcium and magnesium vortexed for $1 \mathrm{~min}$. The mixture was left to stand at room temperature for $1 \mathrm{~h}$ and then centrifuged at $948 \mathrm{xg}$ for 10 minutes at room temperature. The supernatant was transferred to a new tube and centrifuged again for 10 minutes at the highest speed. The supernatant was sterilize by filtration $(0.22$ micron filter) and stored at in $-80^{\circ} \mathrm{C}$ until used.

\subsection{Mice and Dosing}

A total of 30 female wild-type Balb/c mice, between the ages of 7-8 weeks were used. All animals were fed standard rodent chow (Purina 5001) and provided water or M. tea ad libitum throughout the study. Fresh water and M. tea was offered daily for 7 days. At the time of each water/M. tea change, fluid consumption was recorded by subtracting the amount of water left from the amount of water given. The average daily consumption per mouse was determined by dividing the total water consumption of each cage was by the number of mice per cage. In addition, weights and chow consumption were recorded daily. All mice were maintained in the laboratory animal research unit of North Carolina Agrisultural and Technical State University and used in accordance with applicable regulations after institutional approval.

\subsection{Induction of Inflammation}

Because mice are obligate nose breathers, liquid is aspirated during normal respiration and inflammation was induced via the intranasal challenge method as described elsewhere (Minor et al., 2012). Briefly, mice were lightly 
anesthetized with isoflurane. Then either sterile/endotoxin free phosphate-buffered saline (PBS) (Fisher Scientific, Pittsburgh, Pennsylvania), LPS [Sigma, St. Louis, MO \#L4391 $\mu \mathrm{g} \mathrm{mL} \mathrm{m}^{-1}$ ], or dust extracts $(10 \%)$ was applied with a micropipette (50 $\left.\mu \mathrm{L}^{-1}\right)$ to the nares. After inhalation of the droplet was complete the mice were returned to their cage.

\subsection{Necropsy, Tissue, BAL Collection and Protein Assay}

On day 8, $24 \mathrm{~h}$ after intranasal installation, mice were euthanized by $\mathrm{CO}_{2}$ inhalation and Bronchoalveolar Lavage (BAL) was performed on the left lobe of the lung with $1 \mathrm{X}$ PBS. Total protein levels within the BAL fluid were measured by Bradford assay (Bio-Rad Laboratories, Hercules, CA) per manufacturer's instructions.

\subsection{Cell Analysis}

For cell analysis BAL was centrifuged at $300 \times \mathrm{g}$ for $10 \mathrm{~min}$. The cell pellets from bronchoalveolar lavage fluid were resuspended in $200 \mu \mathrm{L}$ of PBS. For flow cytometry analysis side scatter and forward Scatter analysis of the resuspended cells fluid was conducted using an Accuri C6 flow cytometer (BD), collecting 25,000 cells. The percent cells in the live gate were plotted. Differential cell stain was also performed on resuspended cells as described (Minor et al., 2012). Briefly, cells were affixed to glass slides using a Shandon cytospin 4 (Thermo Fisher Scientific Waltham, Massachusetts) at $700 \mathrm{rpm}$ for $5 \mathrm{~min}$. Slides were dried, fixed, stained using HEMA-3 stain (Fisher Scientific, Pittsburg, Pennsylvania) and using a compound light microscope with a $100 \times$ oil immersion lens, a minimum of 200 total cells per slide were identified and counted based on color and morphology. Differential cell analysis to distinguish normal and apoptotic morphology was conducted on the HEMA-3 stained slides counting a minimum of 200 neutrophils per slide. Apoptosis was assessed by changes in nuclear morphology as described in (Rytila et al., 2006). Briefly normal neutrophils have nuclei with at least two lobes connected by chromatin bridges. Cells determined to be undergoing apoptosis had lost chromatin bridges and had condensed nuclei. Pictures of cells was completed using a Zeiss Axio Imager m2m Optical Microscope (Carl Zeiss Microscopy $\mathrm{GmbH}$, Jena, Germany) at $1000 \mathrm{X}$ magnification.

\subsection{Cytokine Assays}

TNF- $\alpha$ ELISA (Bio Legend, San Diego, California) was performed on the BAL fluid following manufacturer's protocols. Plates were read at $405 \mathrm{~nm}$ using a VersaMax microplate reader (Molecular Devices, Sunnyvale, CA). Harvested right lung lobes were stored in $-80^{\circ} \mathrm{C}$ and later used to prepare protein extracts for cytokine array analysis and western blot. Cytokine array analysis was performed using the Proteome Profiler Mouse Cytokine Array Kit, panel A catalog\#ARY006 ( $\mathrm{R}$ and D systems, Minneapolis, $\mathrm{MN}$ ) with extracts prepared from the middle lobes of the right lung that were homogenized per manufacturer's instructions. Briefly, lung tissue was homogenized with a pellet pestle grinder and cordless mixer motor in PBS with $1 \mathrm{X}$ protease inhibitors (Pierce Rockford, IL\#78439). Triton X-100 was added to the homogenate to a final concentration of $1 \%$. The samples were frozen at $-80^{\circ} \mathrm{C}$, overnight. After thawing, the samples were centrifuged at 10,000 $\mathrm{g}$ for 5 min to remove cellular debris. Protein quantitation of sample extracts was performed (Pierce Rockford, IL). Each of the four protein array blots supplied with the kit were incubated with $300 \mu \mathrm{g}$ of total protein.

\subsection{Western Blot}

Protein extraction for western blot were prepared by homogenizing upper right lung lobes with a pellet pestle grinder and cordless mixer motor in $200 \mathrm{~mL}$ of 1X RIPA buffer supplemented with protease and phosphatase inhibitors (Pierce Rockford, IL). Homogenates were centrifuged at 10,000 g for $5 \mathrm{~min}$. Whole cell lysates were collected and quantified by protein assay (Pierce Rockford, IL). Total protein extracts [30 $\mu \mathrm{g}$ well] from lung were separated via SDS-PAGE, transferred to nitrocellulose membranes and probed with anti-mouse p-JNK (Santa Cruz, Santa Cruz California (sc-6254) and anti-mouse JNK (sc7345). Cytokine arrays and western blot images were developed and analyzed for densitometry using the ChemiDoc system (Bio Rad, Hercules, CA) imaging system and ImageLab software.

\subsection{Statistical Analysis}

GraphPad Prism version 5 (La Jolla, CA) was used to create graphs and conduct all statistical analysis. $\mathrm{P}$ values less than 0.05 were considered significant. There were five mice in each of the experimental condition; water+PBS, M. tea+PBS, water+LPS, M. tea+LPS, water+10\% DE, M. tea+DE. Statistical power as determined using a statistical power calculator from DSS research was greater than $95 \%$ for data where there were 2 fold increases. 


\section{RESULTS}

\subsection{Dosing and Weight}

In order to evaluate the anti-inflammatory role of Moringa tea in acute lung inflammation induced by occupation dust exposure we developed a mouse model. Mice were given fresh Moringa tea prepared from dried Moringa leaves daily for seven days. We found no significant differences in weight gain or food consumption between the two groups; water and M. tea (Fig. 1B and C). Moreover, mice in the tea group consumed $\mathrm{M}$. tea at the same rate and at times better (Fig. 1A; days 1 and 6-8) than the control mice consumed water.

\subsection{Analysis of Inflammation; Cellular Influx and Protein Expression}

Inflammatory responses are associated with increases in vascular permeabilization and cellular influx. Figure $\mathbf{2 A}$ shows that while the level of total protein increased after exposure to LPS and $10 \%$ DE, mice that consumed M. tea had significantly less protein in the BAL fluid $24 \mathrm{~h}$ after inhaling the DE as compared to mice that consumed water (Fig. 2A). To compare cellular influx, flow cytometry was performed on the BAL fluid collected 24 $\mathrm{h}$ after intranasal inhalation of PBS, LPS or $10 \%$ DE. Figure 2B and $\mathbf{C}$ show that mice that drank water had significantly more cells in the BAL of mice exposed to 10\% DE (Fig. 2B and C). But, cellular influx into the lung after challenge with DE was significantly $(\mathrm{p}<0.0001)$ lower in mice that consumed Moringa tea (Fig. 2B and C). These data suggesting that there was less inflammation in the lung of mice that consumed the M. tea.

In humans and animals, lung challenge with Lipopolysaccharide (LPS) causes a neutrophil-rich inflammatory responses and intranasal instillation of swine confinement dust extracts in mice has been shown to lead to increased cellular inflammation that is predominated by neutrophils (Sandström et al., 1994) (Jagielo et al., 1996; Poole et al., 2009). Differential cell analysis of the cells collected from the BAL show that neutrophils were the predominant cell type detected in the in the lungs $24 \mathrm{~h}$ after LPS and $10 \%$ DE challenge (Fig. 2D). Interestingly, there were no significant differences between the total macrophage, neutrophil, or lymphocytes (no other WBC types were observed) in the BAL of mice that consumed water or Moringa tea (Fig. 2D). Through further analysis of neutrophils, using nuclear morphology to distiguish neutrophil viability we determined that after LPS challenge in both water and M. tea groups there were few neutrophils with apoptotic nuclear morphology (Fig. 3A and B). However, after challenge with $10 \%$ DE there were significantly $(\mathrm{p}<0.05)$ more apoptotic neutrophils $(50.3 \%)$ present in the mice that drank the Moringa tea as compared to the mice that drank water $(24.1 \%)$ (Fig. 3A and B). Taken together this suggests that consumption of Moringa Tea resulted in had less inflammation through a mechanism that involved neutrophil viability.

\subsection{Cytokine Expression}

TNF- $\alpha$, is a cytokine associated with proinflammatory responses. However, divergent roles for TNF- $\alpha$ have been reported. Van Den Berg et al. (2001) reported neutrophils exposed to low concentrations $[<1.0$ $\mathrm{ng} \mathrm{mL} \mathrm{m}^{-1}$ ] of TNF- $\alpha$ have increased survival while higher concentrations of TNF- $\alpha$ [10-100 $\left.\mathrm{ng} \mathrm{mL}^{-1}\right]$, induce apoptosis (Van Den Berg et al., 2001). TNF- $\alpha$ ELISA was performed on BAL collected $24 \mathrm{~h}$ post inhalation. We report that, as one might expect, TNF- $\alpha$ expression was induced by LPS and $10 \%$ DE both the water and M. tea groups. However, TNF- $\alpha$ expression was significantly greater in mice from the $M$. tea group after challenge with $10 \%$ DE compared to mice in the water group with the same challenge (Fig. 4). This level of TNF- $\alpha$ [average $1.0 \mathrm{ng} \mathrm{mL}^{-1}$ ] while not at the level described by Van Den Berg et al. (2001) to cause apoptosis it is potentially greater than the level that provides protection and therefore may have led to the increased incidence of apoptosis in neutrophils detected in the BALF collected from mice that consumed M. tea after inhalation of $10 \%$ DE observed in Fig. 3.

In addition to preventing or inducing apoptosis, TNF$\alpha$ expression can also induce the expression of other cytokines that have pro and anti-inflammatory functions. Therefore we sought to determine the expression levels of other pro and anti-inflammatory cytokines in the lung after challenge with $10 \%$ DE. Lung protein extracts were analyzed by cytokine array comparing PBS and 10\% DE challenged mice, since that was the condition that resulted in a greater significant difference in TNF- $\alpha$ production. We had positive reactions with 17 of the 40 total cytokine antibodies spotted on the array (Fig. 5A) and report changes of two-fold or greater in 11 of the 17 cytokines detected. Namely; Tumor Necrosis Factor (TNF)- $\alpha$ Keratinocyte Chemoattractant (KC), Triggering Receptor Expressed on Myeloid cells-1 (TREM-1), Macrophage-Colony Stimulating Factor (MCSF), Macrophage Inflammatory Protein-(MIP) $1-\alpha$, MIP-2, IL-16, IL-1 $\alpha / \beta$, Regulated upon Activation, Normal $\mathrm{T}$ cell Expressed and Secreted (RANTES) and IL-1 receptor antagonist (IL-1ra) (Fig. 5B). 

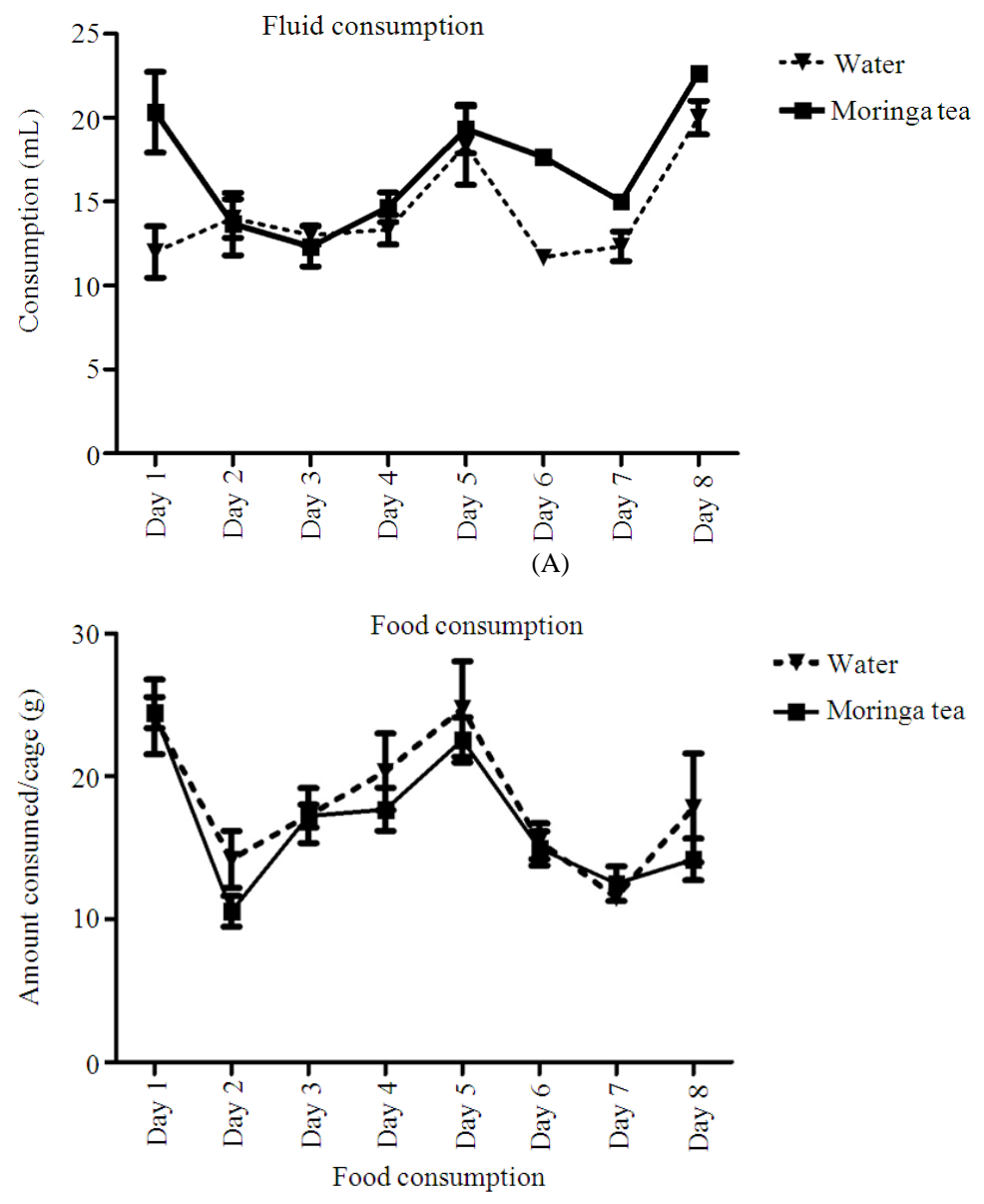

(B)

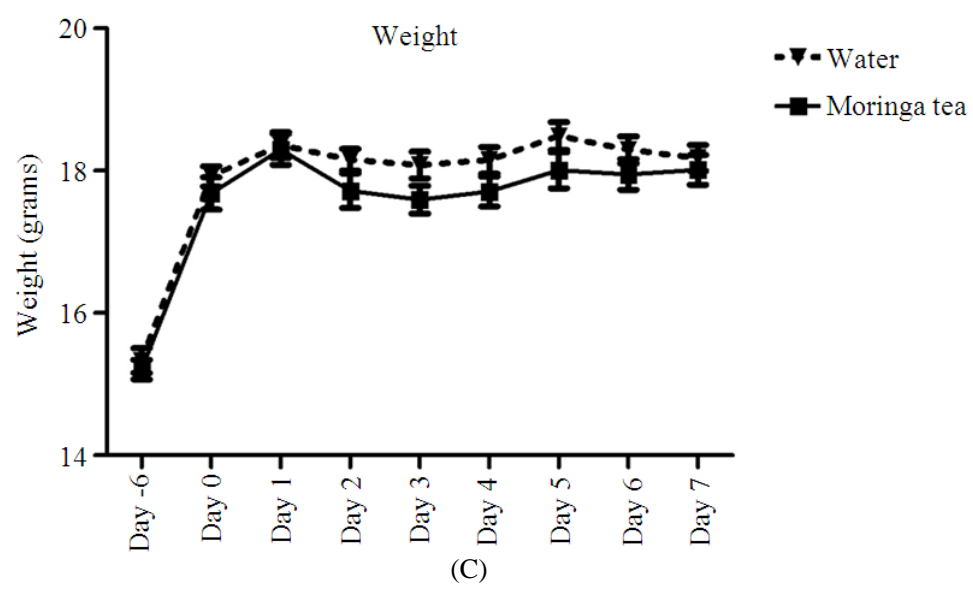

Fig. 1. Fluid, food consumption and weight gain of mice. For (A and B) water and feed consumption was measured daily during the eight day trial. Total average water and feed consumption was calculated to find average daily consumption per mouse by dividing the total amount consumed by the number of mice per cage. Data are expressed as means \pm SD. For water and tea consumption in (A) a two-way repeated measures ANOVA with a 95\% confidence level was used to determine significance $(* *=p<0.001, *=p<0.05)$. (C) All mice were weighed daily on an Arbor 1605 electronic balance. In all graphs, data are an average of 15 mice per group. 
Mykea Mcknight et al. / American Journal of Immunology 10 (2): 73-87, 2014

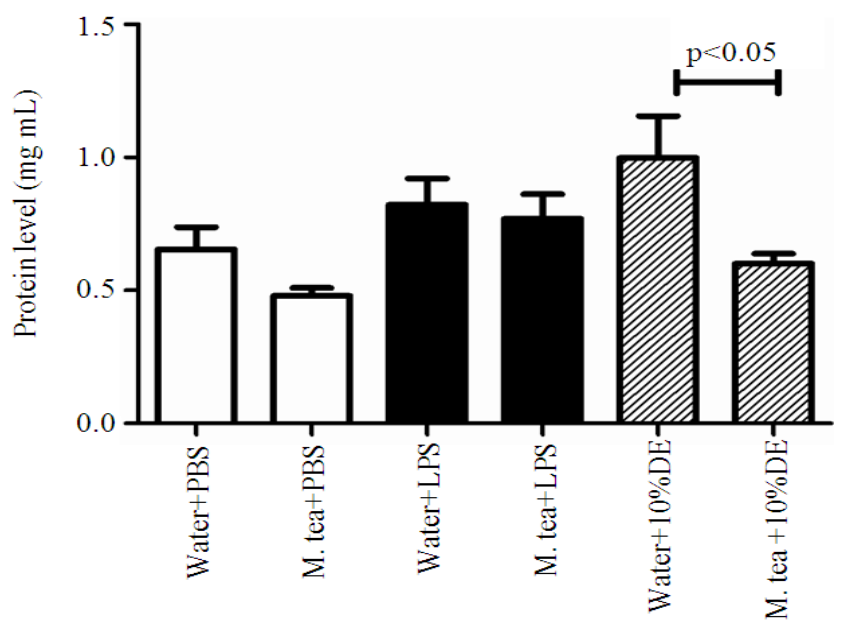

(A)
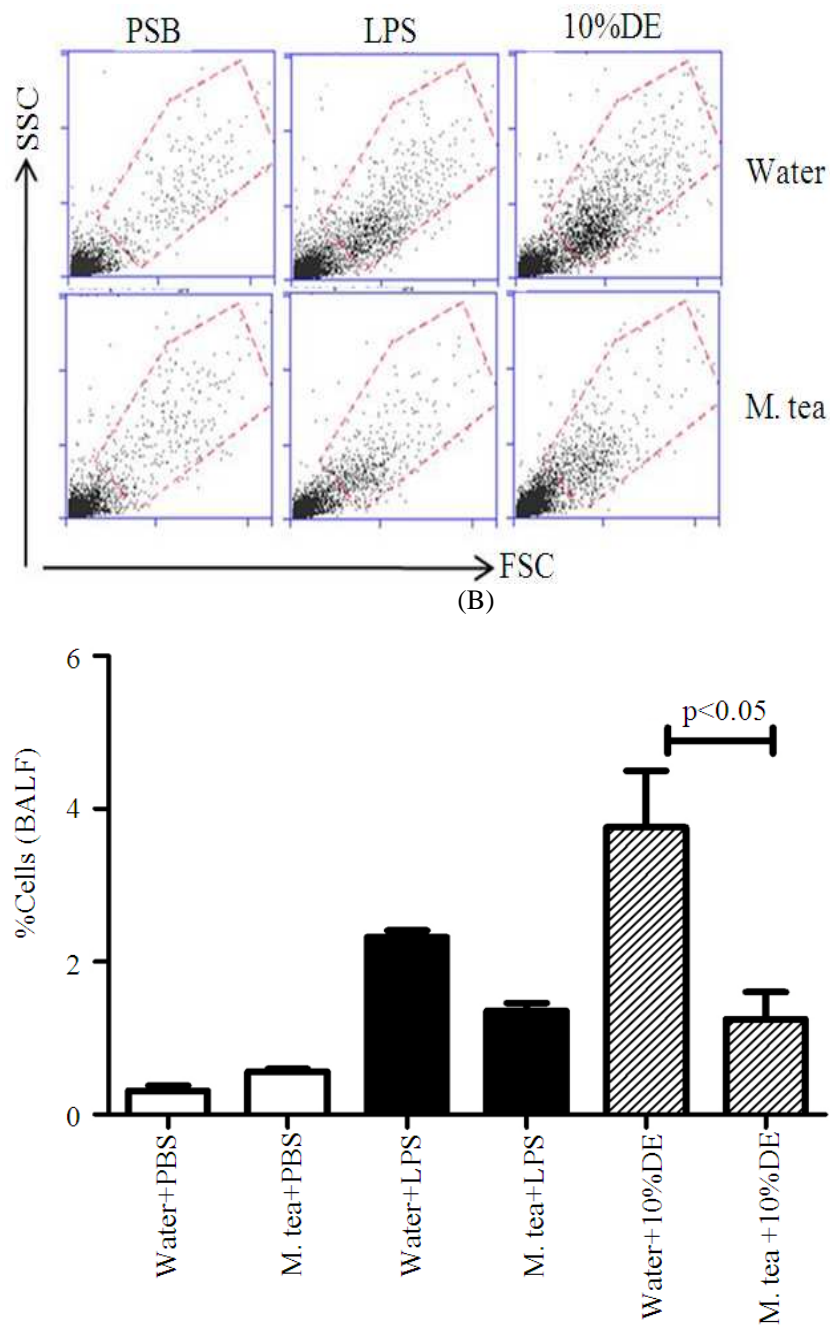

(C) 

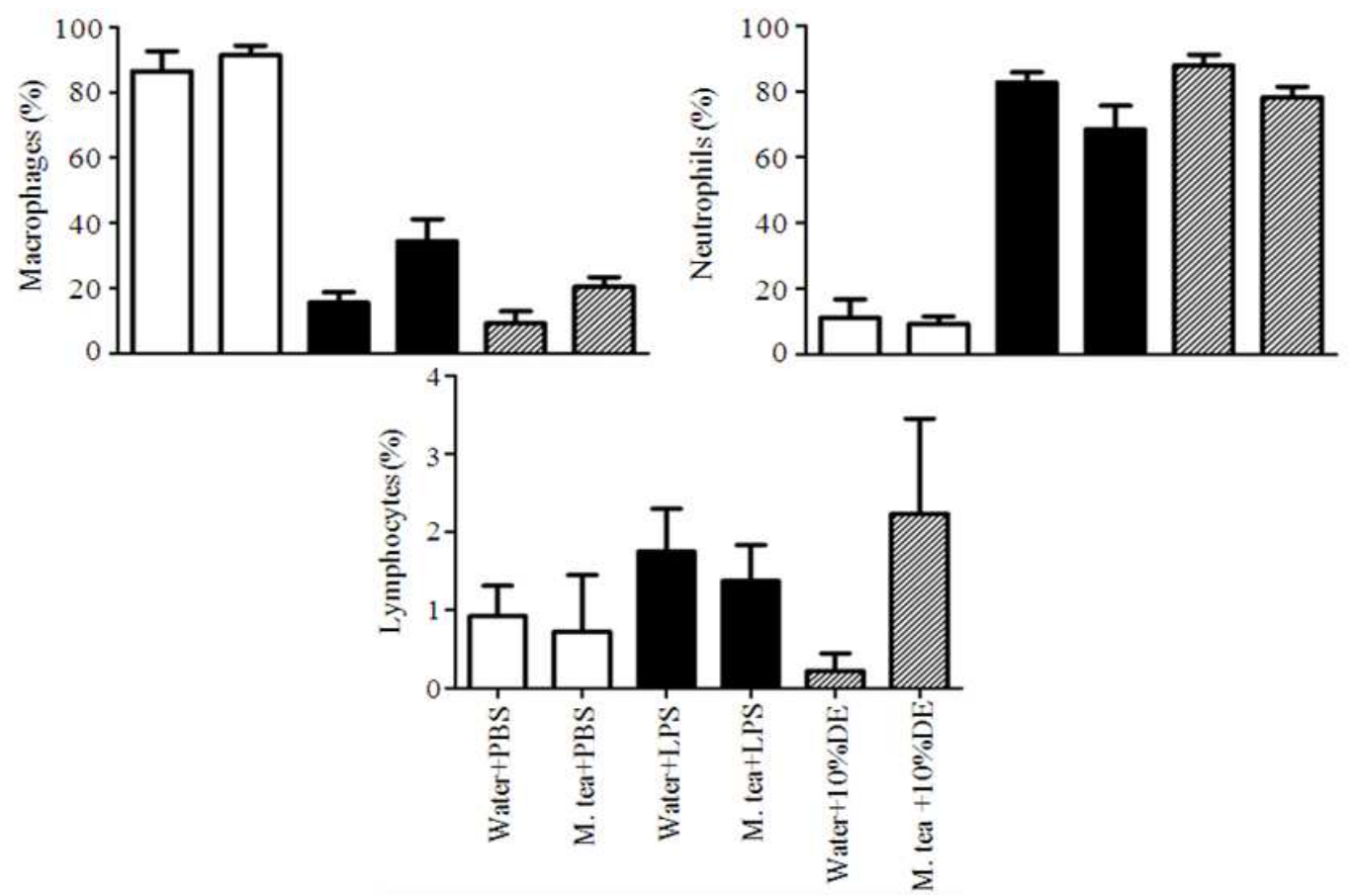

(D)

Fig. 2. (A) Protein levels within the BALF were measured $24 \mathrm{~h}$ after inhalation challenge. Shown are the average levels for each condition $(n=5)$. One-way ANOVA analysis with Bonferroni's multiple comparison test with a $95 \%$ confidence level was used to determine significance. (B) Representative dot plots of BALF cells analyzed by flow cytometry for size and granularity. (C) Histogram of the flow cytometry data showing the average $(n=5)$ percent cell data obtained for each experimental treatment. One-way ANOVA with Bonferroni's Multiple Comparison Test with a 95\% confidence level was used to determine significance. (D) For differential cell analysis, data are averaged from an $\mathrm{n}$ of five in each group and are expressed as means $\pm \mathrm{SD}$

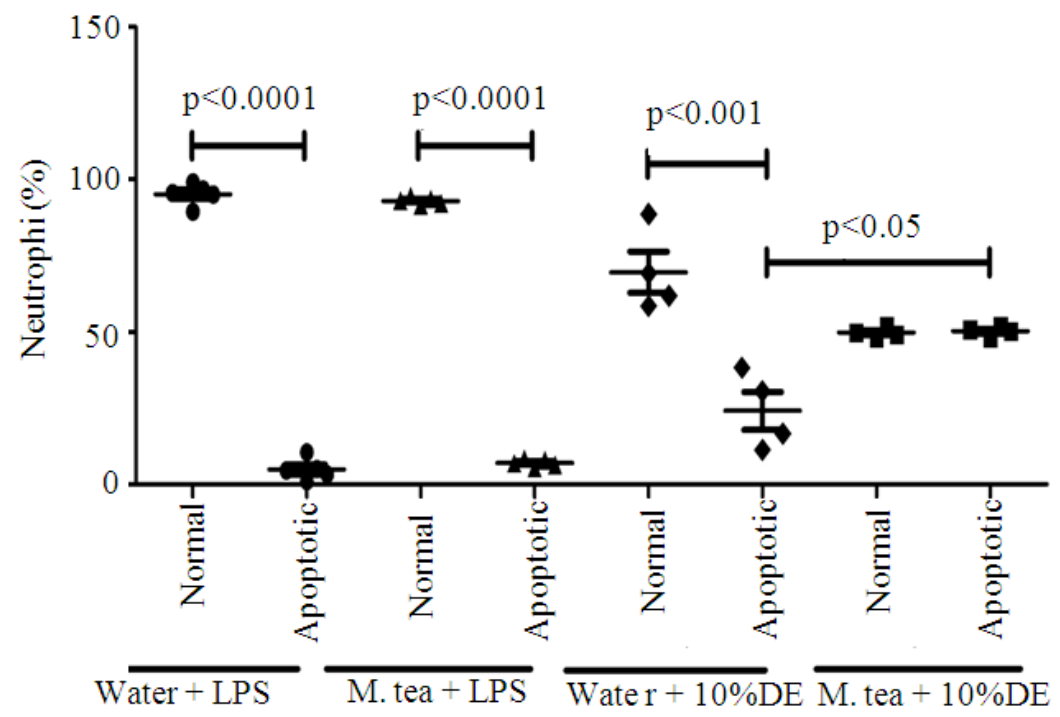

(A) 


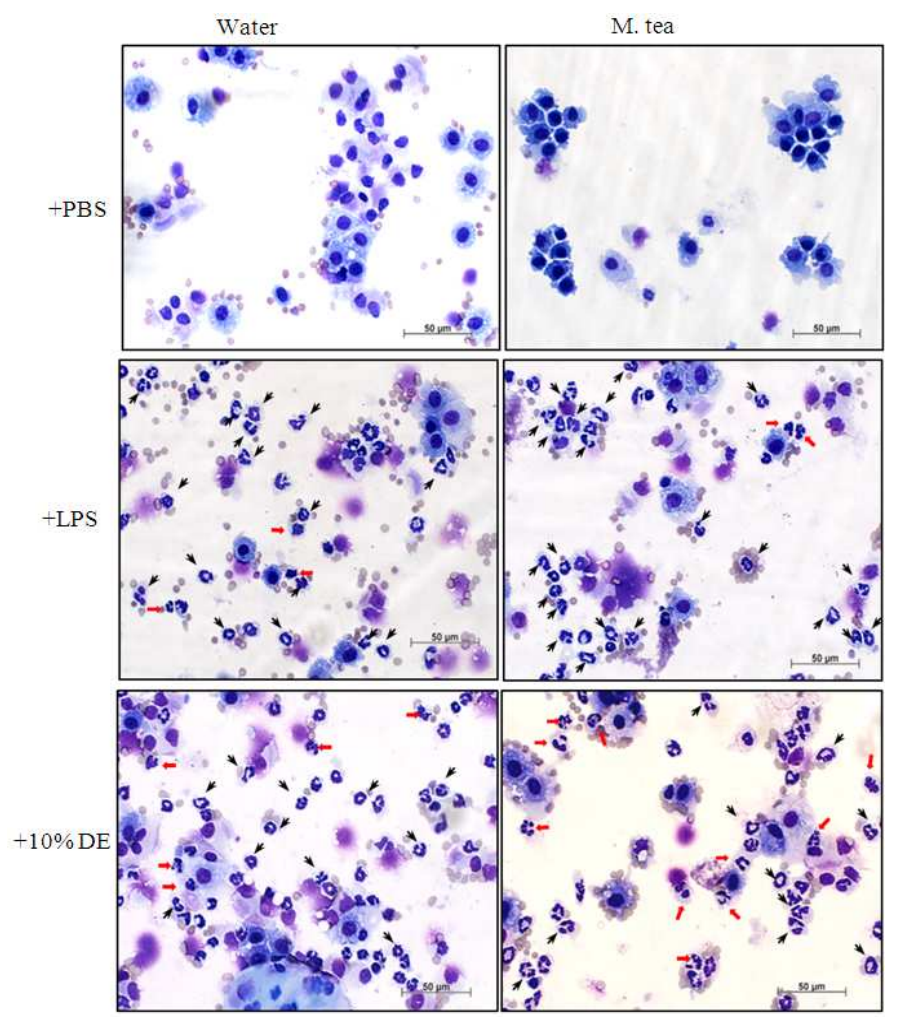

(B)

Fig. 3. (A) Slides prepared for differential cell analysis (Figure 2D) were also used to evaluate neutrophil apoptosis. A total of 200 neutrophils per slide were counted using $100 \mathrm{X}$ magnifications and oil immersion. Before counting, slides were deidentified. Data are an average $(\mathrm{n}=5)$ in each condition and are expressed as means \pm SD. One-way ANOVA with Bonferroni's Multiple Comparison Test with a 95\% confidence level was used to determine significance. (B) Representative slides showing normal (black arrows) and apoptotic neutrophils (red arrow heads)

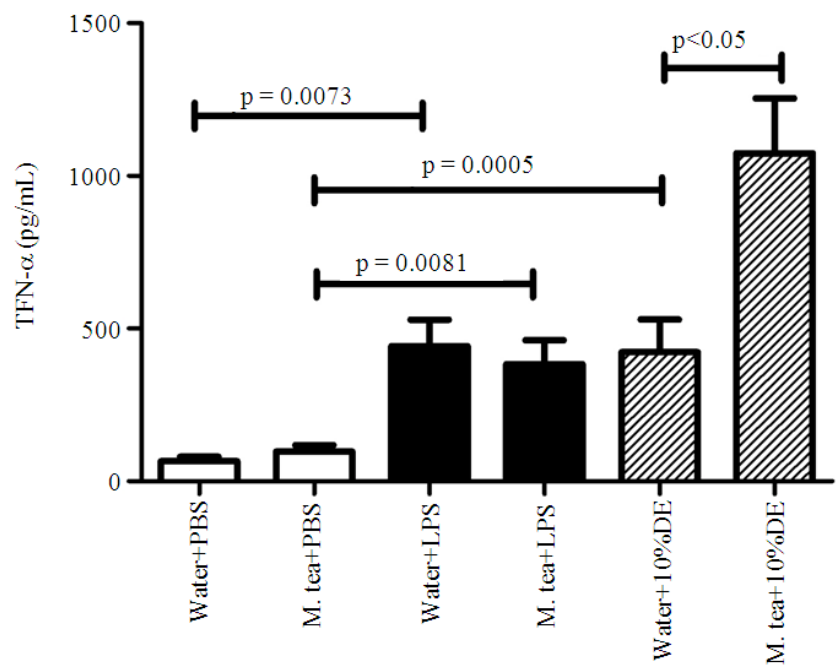

Fig. 4. TNF- $\alpha$ ELISA on BAL fluid collected 24h post inhalation challenge. ELISA was conducted per manufacturer's directions. Data are an average of $n=5$ in each group. Data are expressed as means \pm SD and were compared using a two-tailed unpaired Student $t$ test with a $95 \%$ confidence level 

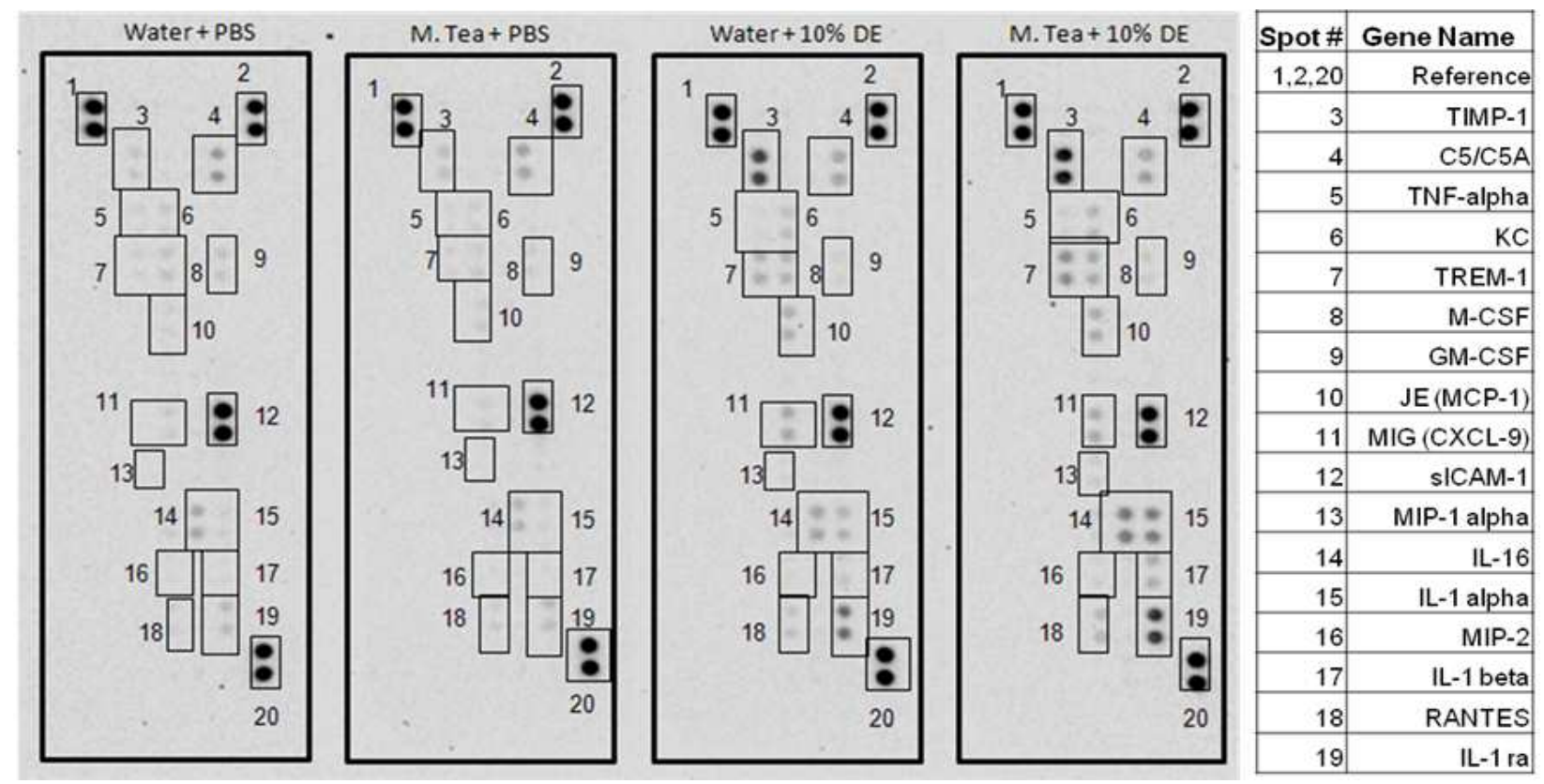

(A)

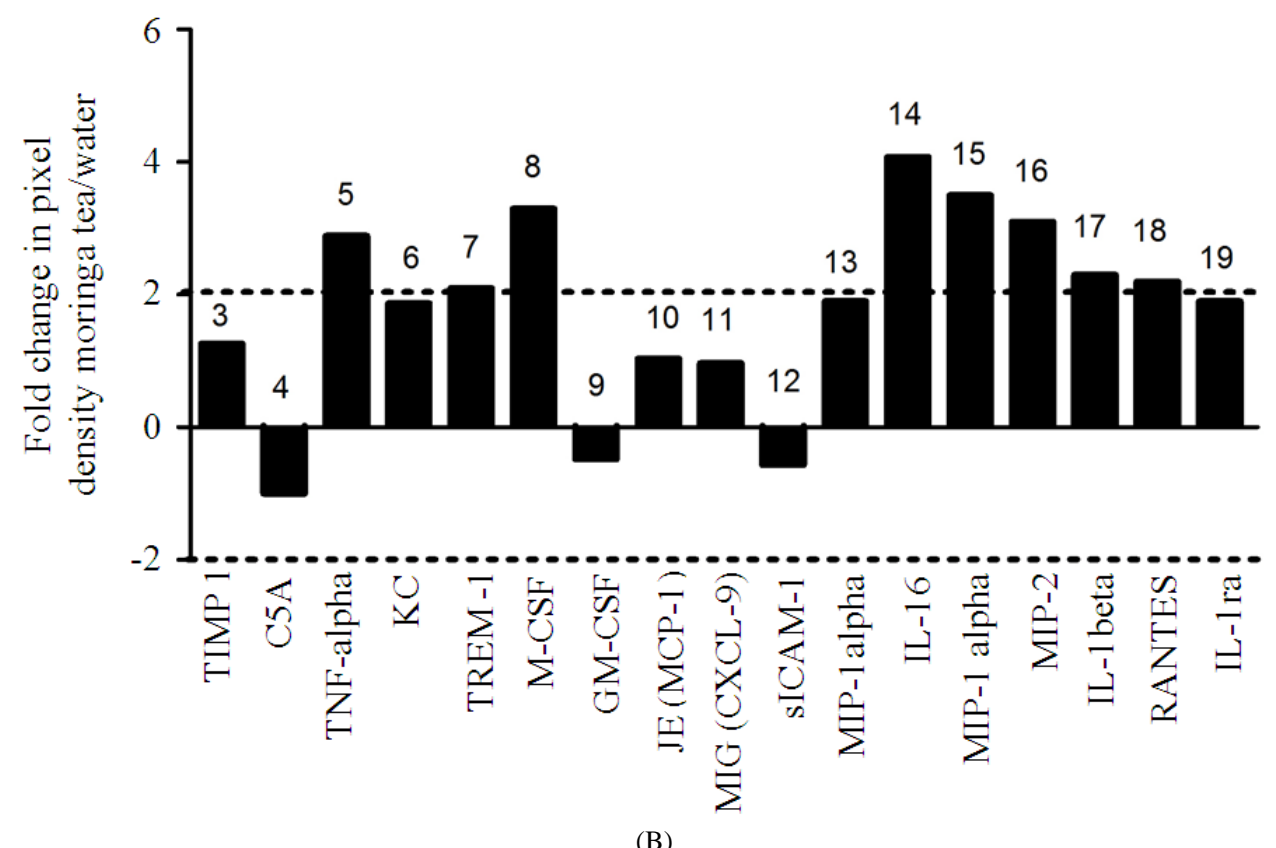

(B)

Fig. 5. (A) Lung tissue lysates were prepared by homogenization in $1 \mathrm{X}$ ice cold PBS with protease inhibitors. Each array was probed with $300 \mu \mathrm{g}$ of lung lysate prepared from pooled lung tissues $(\mathrm{n}=5$ for each blot). (B) Densitometry was performed on the spots with gel-doc system software. First density for the pair of spots were averaged, then averages were then normalized to the average density of the reference spots. Next, the normalized densities of lung lysates from PBS treated mice were subtracted from the normalized densities of the DE treated lungs (M. tea+DE-M. tea+PBS and water+DE-water+PBS). Finally the normalized M. Tea+DE with PBS subtracted values were divided by water + DE with PBS subtracted values. The dotted line represents the 2 fold cut-off 


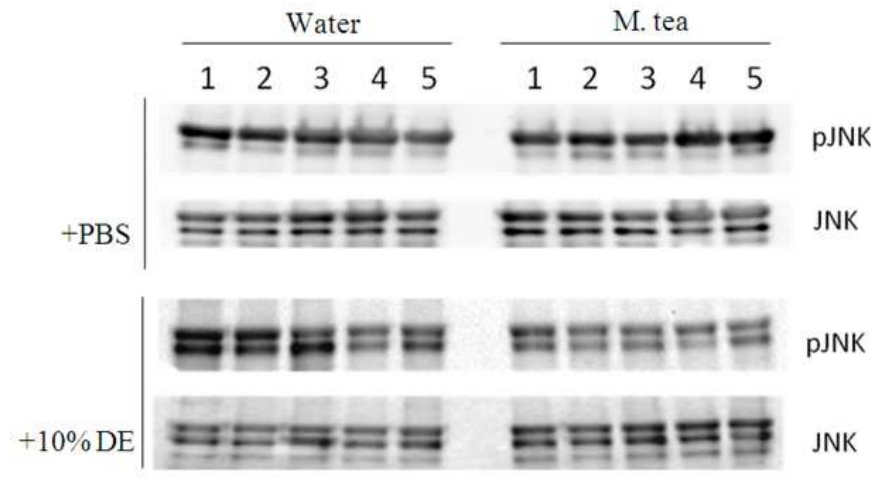

(A)

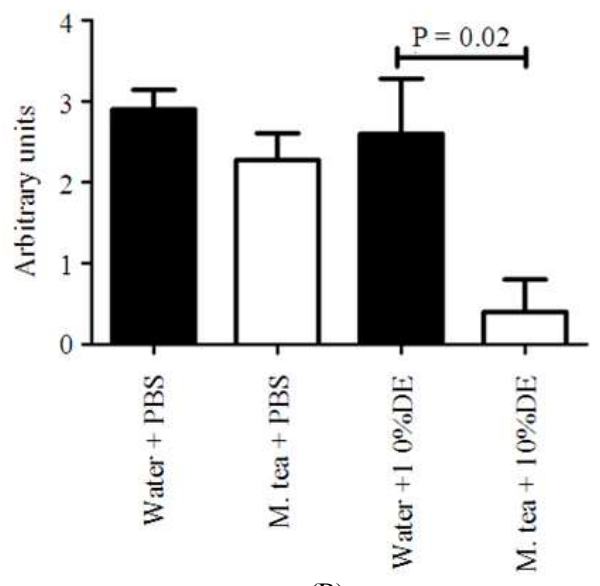

(B)

Fig. 6. (A) Total protein extracts from lungs were separated via SDS-PAGE, transferred to nitrocellulose membranes and probed for p-JNK and total JNK. (A) Each lane represents extracts prepared from an individual animal $(n=5)$. (B) Average change in pJNK activation was determined through densitometric analysis of the protein bands for JNK and pJNK. Data is expressed as a ratio between the density of $\mathrm{p}-\mathrm{JNK}$ divided by that of total JNK $(n=5)$. Data are expressed as means \pm SD and were compared using a two-tailed unpaired Student $t$ test with a 95\% confidence level

\subsection{MAP Kinase Activation}

The c-Jun N-terminal Kinases/Stress-Activated Protein Kinase (JNK/SAPK) is a member of the Mitogen-Activated Protein Kinase (MAPK) superfamily, which are activated in response to LPS and contribute to inflammatory responses (Ip and Davis, 1998). Inhibition of JNK/MAPK signaling is a targeted strategy of reducing inflammation (Kaminska, 2005). Therefore, we investigated whether tea brewed from dried Moringa leaves would inhibit the activation of JNK/MAPK pathway. Western blot analysis of protein extracts prepared from the lungs 24 $\mathrm{h}$ post intranasal challenge show decreased activation of JNK in animals that drank Moringa tea as compared to those that drank water (Fig. 6).

\section{DISCUSSION}

Asthma and allergy combined are the leading chronic diseases in the United States and respiratory disease is one of the main chronic conditions among farmers and their families (Freund et al., 2010). Farm environments contain several particulates (e.g., feed grain, fecal matter, animal dander and traces of bacteria and mold) that may pose inhalation exposure risk to agricultural workers and their families. Inhalation of endotoxins and carbon dioxide at levels above the recommended health threshold limits (Mc Donnell et al., 2008) can lead to acute and chronic airway inflammation (Schierl et al.,
2007). Poole et al. (2009) reported increased cellular inflammation, predominated by neutrophils, in mouse BALF following a single intranasal instillation of DE.

Vitamins, minerals, antioxidants and other active compounds present in plants and plant-based materials can modulate immune responses and alleviate inflammation. Interestingly, four out of the five classes of drugs that are presently being used as an asthma treatment originate from herbs (Ziment and Tashkin, 2000). For example, green tea brewed from the leaves of the plant Camellia sinensis was found to block the expression of an anti-inflammatory cytokine (Li et al., 2007) and extracts prepared from grape seeds which have potent antioxidant and anti-inflammatory effects were shown to alleviate inflammation and asthma associated pathologies in a mouse model of ovalumin-induced asthma (Mahmoud, 2012). Additionally supplementation of mouse diets with vitamin D [1,25 hydroxyvitamin D], one of the vitamins found in Moringa (Anwar et al., 2007), reduced signatures of lung inflammation (i.e., lung neutrophilia and BAL levels of IL8) in mice exposed to organic dust daily for two weeks compared to mice fed a standard chow (naturally containing low levels of vitamin D) (Golden et al., 2013).

We designed a study to investigate the potential of tea prepared from dried Moringa leaves to block acute lung inflammation after exposure to LPS or dust collected from a swine confinement facility. We found that mice that consumed Moringa tea had fewer cells within the BAL fluid in the lung $24 \mathrm{~h}$ after inhaling $10 \%$ 
DE as detected by flow cytometry (Fig. 2) despite having significantly higher levels of TNF- $\alpha$ than controls in response to the DE (Fig. 4). This is consistent with a previous report by (Mahajan et al., 2009) using a model of ovalbumin-induced airway-inflammation that showed extracts from Moringa seeds improved total differential cell counts in blood and bronchoalveolar lavage fluid, but not levels of TNF- $\alpha$ (Mahajan et al., 2009). More recently, a study by (Kooltheat et al., 2014) was published evaluating the effect of an ethyl acetate fraction of Moringa (MOEF) prepared from fresh leaves on cytokine production by human macrophages exposed to cigarette smoke extract. It was reported that pretreatment of human monocyte derived macrophages with varying concentrations of MOEF abrogated TNF- $\alpha$, IL-6 and IL-8 cytokine production to LPS exposure (Kooltheat et al., 2014). This further illustrates an antiinflammatory role for Moringa. While TNF- $\alpha$, is a cytokine typically associated with pro-inflammatory responses, divergent roles for TNF- $\alpha$ have been reported whereby there are instances where it also has immunosuppressive function. Studies have shown TNF$\alpha$ can both provoke and protect against the induction of apoptosis in neutrophils. Van den Berg et al. (2001) reported neutrophils exposed to low concentrations $[<1.0$ $\mathrm{ng} \mathrm{m}{ }^{-1}$ ] of TNF- $\alpha$ have increased survival while higher concentrations of TNF- $\alpha$ [10-100 $\left.\mathrm{ng} \mathrm{ml} \mathrm{ml}^{-1}\right]$, induce apoptosis (Van Den Berg et al., 2001). Here we show data consistent with this phenomenon, whereby greater numbers of neutrophils with apoptotic morphology were detected in the experimental condition that led to the highest level of TNF- $\alpha$ expression (M. tea+DE) (Fig. 3 and 4) suggesting that the level of TNF- $\alpha$ within the BAL [average $1.0 \mathrm{ng} \mathrm{mL} \mathrm{m}^{-1}$ ] of mice that consumed Moringa tea and inhaled DE may have led to increased incidence of apoptosis of neutrophils in the lung. The decrease in cellular influx detected by flow cytometry but not by differential cell staining may have been due to the dead cells being gated out during cell acquisition as apoptotic cells do not display similar forward and side scatter as viable neutrophils. Reports on Moringa's effect on inflammatory cells such as neutrophils has been inconsistent. Where some report with animal models that Moringa consumption leads to increases in neutrophils and neutrophil function; others find that Moringa can cause decreases in neutrophil levels within the blood (Gupta et al., 2010; Owolabi et al., 2012; Isitua and Ibeh, 2013). Further studies to elucidate the effect of Moringa on neutrophils, specifically induction of apoptosis are needed.
In addition to abrogating or inducing apoptosis, TNF$\alpha$ expression can also induce the expression of other cytokines that have anti-inflammatory functions. Other pro-and anti-inflammatory cytokines were found in this study to be differentially expressed by mice that consumed Moringa tea. We report that after DE exposure, mice that consumed $\mathrm{M}$. tea had 2 fold or higher increases in the levels of proinflammatory/chemotactic cytokines (IL-1 $\beta$ and $\alpha, \mathrm{KC}$, M-CSF, RANTES, MIP-2 and MIP1- $\alpha$, in the lung, as compared to mice that drank water. We also observed increases in immunosuppressive cytokines IL-6, IL-1Ra and TREM-1 (De Bie et al., 2002; Okada et al., 1995; Little and Cruikshank, 2004; Gibot and Massin, 2006; Giamarellos-Bourboulis et al., 2008).

IL-1 $\beta$ or TNF- $\alpha$ expression can lead to increased IL-16 expression by epithelial cells (Little et al., 2003) a cytokine with an immunomodulatory role in asthmatic inflammation (De Bie et al., 2002; McFadden et al., 2007). IL-1Ra is an antagonist to IL-1 $\alpha / \beta$ signaling in the lung (Wilmott et al., 1998). It is produced at high levels by neutrophils in response to LPS stimulation or exposure to TNF- $\alpha$ (McColl et al., 1992; Nguyen et al., 2010) and in a guinea pig model of late asthmatic reactions (Okada et al., 1995). Ning and colleagues investigated mice with acute lung inflammation and reported a positive correlation in expression pattern between TREM-1 and TNF- $\alpha$ whereby both increased with LPS treatment (Liu et al., 2010).

TREM-1 is expressed by neutrophils, monocytes and macrophages (Bouchon et al., 2000). Moreover, the active form of vitamin D, 1, $25(\mathrm{OH})(2) \mathrm{D}(3)$, found in high levels in Moringa (Anwar et al., 2007) induces the expression of TREM-1 by Normal Human Bronchial Epithelial (NHBE) cells. Activation of TREM-1 leads to expression of $\beta$-defensin-2 and TNF- $\alpha$ (Rigo et al., 2012). During bacterial infections TREM-1 accelerates the elimination of bacteria and therefore has a protective role in innate immune responses, but is associated with overwhelming inflammation (Bouchon et al., 2001; Lagler et al., 2009). The membrane form of TREM-1 can be cleaved into a soluble form, sTREM that is released into microenvironment (Gomez-Pina et al., 2007). While, high levels of sTREM-1 have been found in patients with severe forms of allergic asthma (Bucova et al., 2012), it has been suggested that STREM-1 may have an antiinflammatory role, by acting through a mechanism whereby sTREM blocks interactions of membrane-bound TREM-1 with its natural ligand in a way similar to the recognized interaction between the soluble form of the TNF- $\alpha$ receptor and membrane TNF- $\alpha$ receptor (Gibot and Massin, 2006; 
Giamarellos-Bourboulis et al., 2008). Furthermore, it has been suggested that sTREM could be used as therapeutic for inflammatory conditions such as rheumatoid arthritis and sepsis (Kim et al., 2012; Wang et al., 2012). The cytokine array used in this study measures both membrane and soluble forms of TREM-1, therefore, further analysis of the effect of Moringa on this cytokine is needed. In summary, cytokine analysis suggest the within the BAL there was increased expression of antiinflammatory cytokines (IL-16, IL-Ra) that may have helped to mitigate inflammation in the lung.

The Mitogen Activated Protein Kinase proteins (MAPKs) are a group a intracellular signal transduction enzymes found in yeasts, animals and plant cells (Ichimura, 2002). They are triggered in response to extracellular signals and instruct new gene expression, cell survival, growth/proliferation, differentiation or death (Kim and Choi, 2010) in response to the stimuli. LPS treatment of human neutrophils has been shown to activate JNK and JNK activation was shown to be unimportant for LPS-induced TNF- $\alpha$ expression (Arndt et al., 2004). This is constant with our findings where JNK activation is lowest in the condition that gave the highest expression of TNF- $\alpha$ (M. tea+DE). Arndt et al. (2004), demonstrated that systemic treatment of mice with JNK inhibitor SP600125 resulted in inhibition of JNK activation, decreased neutrophil recruitment and a decrease in the microvascular leak in the lungs after LPS inhalation (Arndt et al., 2005). M. oleifera pod, root, leaf and fruit extracts were reported to block inflammatory responses of a macrophage cell line stimulated with LPS by inhibiting MAPK, NF- $\mathrm{BB}$ activation activation (Muangnoi et al., 2012; Lee et al., 2013). In keeping with these studies, we report here that activation of JNK was abrogated in mice that consumed tea made from the leaves of Moringa oleifera and that this was associated with decreases in BAL protein levels (a measure of lung leakage) (Fig. 2A) and decrease in the levels of viable neutrophils (Fig. 3) within the lungs after inhalation of swine confinement facility dust. The effect that Moringa may have had on other MAPK pathway proteins was not evaluated here but is of interest. Research into the immune modulating aspects of Moringa is ongoing and follow up studies, investigating the role of Moringa on cell (neutrophil) migration and viability are planned.

\section{CONCLUSION}

Moringa is being cultivated and sold as a nutritional supplement. It has been reported to alleviate a host of conditions including hepatoxicity (Hamza, 2007), neuropathic pain (Khongrum et al., 2012), oxidative damage (Kirisattayakul et al., 2012) and inflammation (Muangnoi et al., 2012; Lee et al., 2013). Here we present data that suggests immunoprotective and antiinflammatory properties for Moringa that involves regulation of neutrophils in airway inflammation.

\section{ACKNOWLEDGEMENT}

The researchers thank Mr. Livingston Mawutor of Winston-Salem, NC for growing and providing the Moringa leaves used in this study. We also acknowledge, Chakia McKlendon and Dawn Conklin for technical assistance and Dr. Sergey Yarmolenko for technical assistance with neutrophil images. This work supported in part by Grant numbers; NCX-270-5-12-120-1 (to R.C.M), NCX-255-5-11-120-1 (to J.T.W.) and 201138821-30967 (to J.T.W.) each from the USDA National Institute of Food and Agriculture. Its contents are solely the responsibility of the authors and do not necessarily represent the official views of the National Institute of Food and Agriculture.

\section{REFERENCES}

Anwar, F., S. Latif, M. Ashraf and A.H. Gilani, 2007. Moringa Oleifera: A food plant with multiple medicinal uses. Phytotherapy Res., 21: 17-25. DOI: 10.1002/ptr.2023

Arndt, P.G., N. Suzuki, N.J. Avdi, K.C. Malcolm and G.S. Worthen, 2004. Lipopolysaccharide-induced c-Jun NH2-terminal kinase activation in human neutrophils: Role of phosphatidylinositol 3Kinase and Syk-mediated pathways. J. Biol. Chem., 279: 10883-10891. DOI: 10.1074/jbc.M309901200

Arndt, P.G., S.K. Young, J.G. Lieber and M.B. Fessler, 2005. Inhibition of c-Jun N-terminal kinase limits lipopolysaccharide-induced pulmonary neutrophil influx. Am. J. Respiratory Critical Care Med., 171: 978-986. DOI: 10.1164/rccm.200406-712OC

Bailey, R.L., J.J. Gahche, C.V. Lentino, J T. Dwyer and J.S. Engel et al., 2011. Dietary supplement use in the United States, 2003-2006. J. Nutr., 141: 261266. DOI: $10.3945 /$ jn. 110.133025

Bouchon, A., J. Dietrich and M. Colonna, 2000. Cutting edge: Inflammatory responses can be triggered by TREM-1, a novel receptor expressed on neutrophils and monocytes. J. Immunol., 164: 4991-4995. DOI: 10.4049/jimmunol.164.10.4991 
Bouchon, A., F. Facchetti, M.A. Weigand and M. Colonna, 2001. TREM-1 amplifies inflammation and is a crucial mediator of septic shock. Nature, 410: $1103-1107 . \quad$ DOI: 10.1016/J.CCC.2010.12.006

Bucova, M., M. Suchankova, M. Dzurilla, M. Vrlik and H. Novosadova et al., 2012. Inflammatory marker strem-1 reflects the clinical stage and respiratory tract obstruction in allergic asthma bronchiale patients and correlates with number of neutrophils. Mediators Inflammat., 2012: 8-8. DOI: $10.1155 / 2012 / 628754$

De Bie, J.J., E.H. Jonker, P.A.J. Henricks, J. Hoevenaars and F.F. Little et al., 2002. Exogenous interleukin16 inhibits antigen-induced airway hyper-reactivity, eosinophilia and Th2-type cytokine production in mice. Clin. Exp. Allergy, 32: 1651-1658. DOI: 10.1046/j.1365-2222.2002.01528.x

Fahey, J.W., 2005. Moringa Oleifera: A review of the medical evidence for its nutritional, therapeutic and prophylactic properties. Part 1. Trees Life J.

Freund, A., A.V. Orjalo, P.Y. Desprez and J. Campisi, 2010. Inflammatory networks during cellular senescence: Causes and consequences. Trends Mol. Med., 16: 238-246. DOI: 10.1016/j.molmed.2010.03.003

Giamarellos-Bourboulis, E.J., M. Mouktaroudi, T. Tsaganos, P. Koutoukas and E. Spyridaki et al., 2008. Evidence for the participation of soluble triggering receptor expressed on myeloid cells-1 in the systemic inflammatory response syndrome after multiple Trauma. J. Trauma., 65: 1385-1390. DOI: $10.1097 /$ TA.0b013e31814699cc

Gibot, S. and F. Massin, 2006. Soluble form of the triggering receptor expressed on myeloid cells 1 : An anti-inflammatory mediator. Intensive Care Med., 32: 185-187. DOI: 10.1007/s00134-0050018-0

Golden, G.A., T.A. Wyatt, D.J. Romberger, D. Reiff and M. McCaskill et al., 2013. Vitamin D treatment modulates organic dust-induced cellular and airway inflammatory consequences. J. Biochem. Mol. Toxicol., 27: 77-86. DOI: 10.1002/jbt. 21467

Gomez-Pina, V., A. Soares-Schanoski, A. RodriguezRojas, C. Del Fresno and F. Garcia et al., 2007. Metalloproteinases shed TREM-1 ectodomain from lipopolysaccharide-stimulated human monocytes. J. Immunol., 179: 4065-4073. DOI: 10.4049/jimmunol.179.6.4065
Gupta, A., M.K. Gautam, R.K. Singh, M.V. Kumar and V. Rao Ch et al., 2010. Immunomodulatory effect of Moringa Oleifera Lam. Extract on cyclophosphamide induced toxicity in mice. Ind. J. Exp. Biol., 48: 1157-1160.

Hamza, A.A., 2007. Curcuma longa, glycyrrhiza glabra and moringa oleifera ameliorate diclofenac-induced hepatoxicity in rats. Am. J. Pharmacol. Toxicol., 2: 80-88. DOI: 10.3844/ajptsp.2007.80.88

Ichimura, K., 2002. Mitogen-activated protein kinase cascades in plants: A new nomenclature. Trends Plant. Sci., 7: 301-308. DOI: 10.1016/S13601385(02)02302-6

Ip, Y.T. and R.J. Davis, 1998. Signal transduction by the c-Jun N-Terminal Kinase (JNK)-from inflammation to development. Curr. Opin. Cell Biol., 10: 205-219. DOI: $10.1016 /$ S0955-0674(98)80143

Isitua, C.C. and I.N. Ibeh, 2013. Toxicological assessment of aqueous extract of moringa oleifera and caulis bambusae leaves in rabbits. J. Clin. Toxicol. DOI: 10.4172/2161-0495.S12-003

Jagielo, P.J., P.S. Thorne, J.L. Watt, K.L. Frees and T.J. Quinn et al., 1996. Grain dust and endotoxin inhalation challenges produce similar inflammatory responses in normal subjects. Chest, 110: 263-270. DOI: $10.1378 /$ chest.110.1.263

Kaminska, B., 2005. MAPK signalling pathways as molecular targets for anti-inflammatory therapyfrom molecular mechanisms to therapeutic benefits. Biochim. Biophys. Acta., 1754: 253-262. DOI: 10.1016/j.bbapap.2005.08.017

Khongrum, J., J. Wattanathorn, S. Muchimapura, W. Thukhum-mee and C. Thipkaew et al., 2012. Moringa oleifera leaves extract attenuates neuropathic pain induced by chronic constriction injury. Am. J. Applied Sci., 9: 1182-1187. DOI: 10.3844/ajassp.2012.1182.1187

Kim, E.K. and E.J. Choi, 2010. Pathological roles of MAPK signaling pathways in human diseases. Biochimica Biophys. Acta. Molecular Basis Dis., 1802: 396-405. DOI: 10.1016/j.bbadis. 2009.12.009

Kim, T.H., S.J. Choi, Y.H. Lee, G.G. Song and J.D. Ji, 2012. Soluble triggering receptor expressed on myeloid cells- 1 as a new therapeutic molecule in rheumatoid arthritis. Med. Hypotheses, 78: 270-272. DOI: 10.1016/j.mehy.2011.10.042

Kirisattayakul, W., J. Wattanathorn, T. Tong-Un, S. Muchimapura and P. Wannanon, 2012. Moringa Oleifera lam mitigates oxidative damage and brain infarct volume in focal cerebral ischemia. Am. J. Applied Sci., 9: 1457-1463. DOI: 10.3844/ajassp. 2012.1457.1463 
Kooltheat, N., R.P. Sranujit, P. Chumark, P. Potup and N. Laytragoon-Lewin et al., 2014. An ethyl acetate fraction of moringa oleifera lam. Inhibits human macrophage cytokine production induced by cigarette smoke. Nutrients, 6: 697-710. DOI: 10.3390/nu6020697

Lagler, H., O. Sharif, I. Haslinger, U. Matt and K. Stich et al., 2009. TREM-1 activation alters the dynamics of pulmonary IRAK-M expression in vivo and improves host defense during pneumococcal pneumonia. J. Immunol., 183: 2027-2036. doi: 10.4049/jimmunol.0803862

Lee, H.J., Y.J. Jeong, T.S. Lee, Y.Y. Park and W.G. Chae et al., 2013. Moringa fruit inhibits LPSinduced NO/iNOS expression through suppressing the NF- $\kappa \mathrm{B}$ activation in RAW264.7 cells. Am. J. Chin. Med., 41: 1109-1123. DOI: 10.1142/S0192415X13500754

Li, W., M. Ashok, J. Li, H. Yang and A.E. Sama et al., 2007. A major ingredient of green tea rescues mice from lethal sepsis partly by inhibiting HMGB1. PloS One, 2: e1153-e1153. DOI: 10.1371/journal.pone.0001153

Little, F.F, E. Lynch, G. Fine, D.M. Center and W.W. Cruikshank, 2003. Tumor necrosis factor- $\alpha$-induced synthesis of interleukin-16 in airway epithelial cells. Am. J. Respiratory Cell Molecular Biol., 28: 354362. DOI: $10.1165 / \mathrm{rcmb}$.2002-0043OC

Little, F.F. and W.W. Cruikshank, 2004. Interleukin-16 and peptide derivatives as immunomodulatory therapy in allergic lung disease. Expert Opin. Biol. Therapy, $\quad 4$ : $\quad 837-846 . \quad$ DOI: 10.1517/14712598.4.6.837

Mahajan, S.G. and A.A. Mehta, 2010. Immunosuppressive activity of ethanolic extract of seeds of moringa oleifera Lam. in experimental immune inflammation. J. Ethnopharmacol., 130: 183-186. DOI: 10.1016/j.jep.2010.04.024

Mahajan, S.G. and A.A. Mehta, 2011. Suppression of ovalbumin-induced Th2-driven airway inflammation by $\beta$-sitosterol in a guinea pig model of asthma. Eur. J. Pharmacol., 650: 458464. DOI: 10.1016/j.ejphar.2010.09.075

Mahajan, S.G., A. Banerjee, B.F. Chauhan, H. Padh and M. Nivsarkar et al., 2009. Inhibitory effect of n-butanol fraction of Moringa Oleifera Lam. seeds on ovalbumin-induced airway inflammation in a guinea pig model of asthma. Int. J. Toxicol., 28: 519-527. DOI: $10.1177 / 1091581809345165$

Mahmoud, Y.I., 2012. Grape seed extract attenuates lung parenchyma pathology in ovalbumin-induced mouse asthma model: An ultrastructural study. Micron., 43: 1050-1059. DOI: 10.1016/j.micron.2012.04.014
Mc Donnell, P.E., M.A. Coggins, V.J. Hogan and G.T. Fleming, 2008. Exposure assessment to airborne contaminants in the indoor environment of Irish swine farms. Ann. Agric. Environ. Med., 15: 323326.

McColl, S.R., R. Paquin, C. Ménard and A.D. Beaulieu, 1992. Human neutrophils produce high levels of the interleukin 1 receptor antagonist in response to granulocyte/macrophage colony-stimulating factor and tumor necrosis factor alpha. J. Exp. Med., 176: 593-598. DOI: 10.1084/jem.176.2.593

McFadden, C., R. Morgan, S. Rahangdale, D. Green and H. Yamasaki et al., 2007. Preferential migration of $\mathrm{T}$ regulatory cells induced by IL-16. J. Immunol., 179: $6439-6445 . \quad$ DOI: $10.4049 /$ jimmunol.179.10.6439

Minor, R.C., M.L. Robinson-Wright, M. Williams and S.L. Hurley, 2012. Dietary $\beta$-glucan leads to increased tnf- $\alpha$ production in the lung. Am. J. Animal Vet. Sci., 7: 55-60. DOI: 10.3844/ajavsp.2012.55.60

Muangnoi, C., P. Chingsuwanrote, P. Praengamthanachoti, S. Svasti and S. Tuntipopipat, 2012. Moringa oleifera pod inhibits inflammatory mediator production by lipopolysaccharidestimulated RAW 264.7 murine macrophage cell lines. Inflammation, 35: 445-455. DOI: 10.1007/s10753-011-9334-4

Nguyen, C.N., P.M. Schnulle, N. Chegini, X. Luo and J.M. Koenig, 2010. Neonatal neutrophils with prolonged survival secrete mediators associated with chronic inflammation. Neonatol., 98: 341-347. DOI: 10.1159/000309007

Liu, N., Q. Gu and Y.S. Zheng, 2010. Expression of triggering receptor-1 in myeloid cells of mice with acute lung injury. World J. Emerg. Med., 1: 144-148.

Okada, S., H. Inoue, K. Yamauchi, H. Iijima and Y. Ohkawara et al., 1995. Potential role of interleukin1 in allergen-induced late asthmatic reactions in guinea pigs: Suppressive effect of interleukin-1 receptor antagonist on late asthmatic reaction. J. Allergy Clin. Immunol., 95: 1236-1245. DOI: 10.1016/S0091-6749(95)70081-1

Owolabi, J.O., E. Opoola and E.A. Caxton-Martins, 2012. Healing and prophylactic effects of moringa oleifera leaf extract on lead induced damage to haematological and bone marrow elements in adult wistar rat models. Open Access Sci. Reports, 1: 386386. DOI: $10.4172 /$ scientificreports. 386 
Pender, R.J., R.C. Minor, S.L. Hurley, D.R. Conklin and J.T. Waterman, 2014. Exposure to swine housing dust modulates macrophage morphology and function. Am. J. Immunol., 10: 35-45. DOI: 10.3844/ajisp.2014.35.45

Poole, J.A., T.A. Wyatt, P.J. Oldenburg, M.K. Elliott and W.W. West et al., 2009. Intranasal organic dust exposure-induced airway adaptation response marked by persistent lung inflammation and pathology in mice. Am. J. Physiol. Lung Cellular Molecular Physiol., 296: L1085-L1095. DOI: 10.1152/ajplung.90622.2008

Rigo, I., L. McMahon, P. Dhawan, S. Christakos and S. Yim et al., 2012. Induction of Triggering Receptor Expressed on Myeloid Cells (TREM-1) in airway epithelial cells by $1,25(\mathrm{OH})(2)$ vitamin $\mathrm{D}(3)$. Innate. Immun., 18: 250-257. DOI: 10.1177/ 1753425911399796

Rytila, P., M. Plataki, F. Bucchieri, M. Uddin and G. Nong et al., 2006. Airway neutrophilia in COPD is not associated with increased neutrophil survival. Eur. Respir. J., 28: 1163-1169. DOI: 10.1183/09031936.00149005

Sandström, T., L. Bjermer and R. Rylander, 1994. Lipopolysaccharide (LPS) inhalation in healthy subjects causes bronchoalveolar neutrophilia, lymphocytosis and fibronectin increase. Am. J. Industrial Med., 25: 103-104. DOI: 10.1002/ajim.4700250127
Schierl, R., A. Heise, U. Egger, F. Schneider and R. Eichelser et al., 2007. Endotoxin concentration in modern animal houses in Southern Bavaria. Ann. Agric. Environ. Med., 14: 129-136.

Sudha, P., S.M. Asdaq, S.S. Dhamingi and G.K. Chandrakala, 2010. Immunomodulatory activity of methanolic leaf extract of moringa oleifera in animals. Ind. J. Physiol. Pharmacol., 54: 133-140.

Van Den Berg, J.M., S. Weyer, J.J. Weening, D. Roos and T.W. Kuijpers, 2001. Divergent effects of tumor necrosis factor $\alpha$ on apoptosis of human neutrophils. J. Leukoc. Biol., 69: 467-473.

Wang, F., S. Liu, S. Wu, Q. Zhu and G. Ou et al., 2012. Blocking TREM-1 signaling prolongs survival of mice with Pseudomonas Aeruginosa induced sepsis. Cell Immunol., 272: 251-258. DOI: 10.1016/j.cellimm.2011.10.006

Wilmott, R.W., J.A. Kitzmiller, M.A. Fiedler and J.M. Stark, 1998. Generation of a transgenic mouse with lung-specific overexpression of the human interleukin-1 receptor antagonist protein. Am. J. Respir. Cell Mol. Biol., 18: 429-434. DOI: 10.1165/ajrcmb.18.3.2983

Ziment, I. and D.P. Tashkin, 2000. Alternative medicine for allergy and asthma. J. Allergy. Clin. Immunol., 106: 603-614. DOI: 10.1067/mai.2000.109432 